\title{
Hemoperitoneum due to bleeding from a vein overlying a subserous uterine myoma: a case report
}

\author{
Samaneh Rokhgireh ${ }^{1}$, Abolfazl Mehdizadeh Kashi ${ }^{1}$, Mohammad Kermansaravi², Banafsheh Tajbakhsh', \\ Leila Allahqoli ${ }^{1}$, Ibrahim Alkatout ${ }^{3 *}$ and Sepideh Khodaverdi ${ }^{4}$
}

\begin{abstract}
Background: Fibroids are the most common pelvic tumors in women; serious complications are rare but can be life-threatening.

Case presentation: We present a case report of a 38-year-old Persian woman with acute abdominal pain and a history of uterine fibroids. The patient refused to undergo a laparoscopic myomectomy. Her ultrasound examination revealed free fluid in the abdominal cavity, and her vital signs were indicative of vasogenic shock. A diagnostic laparoscopy was performed to identify and control the source of bleeding: $400 \mathrm{ml}$ of blood and blood clots were removed. Active bleeding was seen from a vein overlying a subserosal myoma. A laparotomic myomectomy was performed, and the patient was discharged 3 days after surgery with no complications.

Conclusion: Surgeons should consider the possibility of this complication in women with acute abdominal pain and a history of uterine leiomyoma.
\end{abstract}

Keywords: Hemoperitoneum, Subserous myoma, Case report

\section{Background}

Fibroids are the most common pelvic tumors in women [1]; the large majority are asymptomatic and small in size [2]. Symptoms of leiomyoma include abnormal uterine bleeding due to the bulk of the fibroid, as well as reproductive dysfunction [3]. Nevertheless, fibroids may cause serious and acute complications, such as acute urinary retention and renal failure, intraperitoneal hemorrhage, mesenteric vein thrombosis, intestinal gangrene, acute torsion of a subserous leiomyoma, and acute vaginal bleeding [4]. These serious complications are rare but very important for the diagnosis and

\footnotetext{
*Correspondence: kiel.school@uksh.de; ibrahim.alkatout@uksh.de ${ }^{3}$ Department of Obstetrics and Gynecology, University Hospitals Schleswig-Holstein, University Hospitals Campus Kiel, Kiel School of Gynecological Endoscopy, Arnold-Heller-Strasse 3, Haus 24, 24105 Kiel, Germany

Full list of author information is available at the end of the article
}

interdisciplinary differential diagnosis, because they may cause severe morbidity and even mortality. We present a case of intraperitoneal hemorrhage due to a ruptured vein of a subserosal leiomyoma.

\section{Case presentation}

A 38-year-old Persian woman who was a virgin was referred to our emergency ward with right-sided abdominal pain at 11:00 a.m. Her pain had started in the right upper quadrant of the abdomen; its onset was sudden, and it persisted for 2 hours with one fainting episode. The patient's last menstrual period had been 7 days before admission, and she reported no trauma or previous surgery. Her pulse rate was 110 beats/minute; her systolic blood pressure was $80 \mathrm{mmHg}$ and diastolic blood pressure was undetectable; and her body temperature was $37.5{ }^{\circ} \mathrm{C}$. Her abdominal examination revealed

C The Author(s). 2020 Open Access This article is licensed under a Creative Commons Attribution 4.0 International License, which permits use, sharing, adaptation, distribution and reproduction in any medium or format, as long as you give appropriate credit to the original author(s) and the source, provide a link to the Creative Commons licence, and indicate if changes were made. The images or other third party material in this article are included in the article's Creative Commons licence, unless indicated otherwise in a credit line to the material. If material is not included in the article's Creative Commons licence and your intended use is not permitted by statutory regulation or exceeds the permitted use, you will need to obtain permission directly from the copyright holder. To view a copy of this licence, visit http://creativecommons.org/licenses/by/4.0/ The Creative Commons Public Domain Dedication waiver (http://creativecommons.org/publicdomain/zero/1.0/) applies to the data made available in this article, unless otherwise stated in a credit line to the data. 
tenderness in the right lower and upper abdomen. She had an obvious tender mass extending to the umbilicus. She had a history of uterine leiomyoma. Laboratory tests and ultrasound were requested. Her hemoglobin, hematocrit, white blood cell count, and platelet count were $11.1 \mathrm{mg} / \mathrm{dl}, 35 \%, 13.9 \times 10^{3} / \mu \mathrm{L}$, and $333 \times 10^{9} / \mathrm{L}$, respectively. The results of the patient's echocardiogram (echo) and electrocardiogram, Doppler ultrasound of lower limb arteries, troponin enzyme level, and creatine kinase-MB were normal. The report of an ultrasound examination that had already been done revealed an intramural subserosal leiomyoma measuring $9.5 \times 6.5 \mathrm{~cm}$ with cystic degeneration in the fundus of the uterus. Both ovaries were normal, and there was free fluid in the abdominal cavity up to Morison's pouch. Furthermore, a massive fluid collection with internal echoes had been seen in the pelvic cavity, suggestive of a clot. Our differential diagnosis included a ruptured ectopic pregnancy, a hemorrhagic ovarian cyst, and a ruptured ovarian cyst. The patient was admitted to the gynecology ward at 2:00 p.m.

The result of her pregnancy test was negative. At 3:00 p.m., the patient was transferred to the operating room. A diagnostic laparoscopy was performed with the patient under general anesthesia in order to identify and control the source of bleeding. Further reasons for performing the laparoscopy were the patient's unstable hemodynamic condition and the ultrasound report of a hemoperitoneum.

A 10-mm trocar was inserted into the umbilicus, and two 5-mm trocars were placed in the right and left lower quadrants. The hemoperitoneum, consisting of $200 \mathrm{ml}$ of fresh blood and $200 \mathrm{ml}$ of clotted blood, was removed. Laparoscopy revealed a large subserosal leiomyoma $(10 \times 15 \mathrm{~cm})$ located in the fundus of the uterus. The patient's abdomen and pelvis were examined, and a large subserosal leiomyoma $(10 \times 15 \mathrm{~cm})$ was found in the fundus of the uterus, with a congested and dilated venous plexus. On the basis of FIGO (International Federation of Gynecology and Obstetrics) classification of uterine fibroids, the fibroid was a pedunculated subserosal fibroid (type 7). A bleeding vessel was seen on the posterior surface of the leiomyoma (Fig. 1). Because the patient refused to undergo a laparoscopic myomectomy, we performed an abdominal myomectomy (laparotomy), and the uterus was preserved during laparotomy. The patient was discharged with no complications on the third day after the operation. At the control investigation performed 2 weeks after surgery, the patient was in normal condition.

\section{Discussion and conclusions}

The uterine leiomyoma is a benign neoplasm. A variety of approaches are used to treat a uterine leiomyoma, such as observation; medical treatment; surgical myomectomy; and, in rare cases, hysterectomy [5]. Intraperitoneal hemorrhage is a rare complication due to bleeding from uterine leiomyoma [6] and is a lifethreatening condition [7]. The causes of hemoperitoneum in connection with leiomyoma include a ruptured

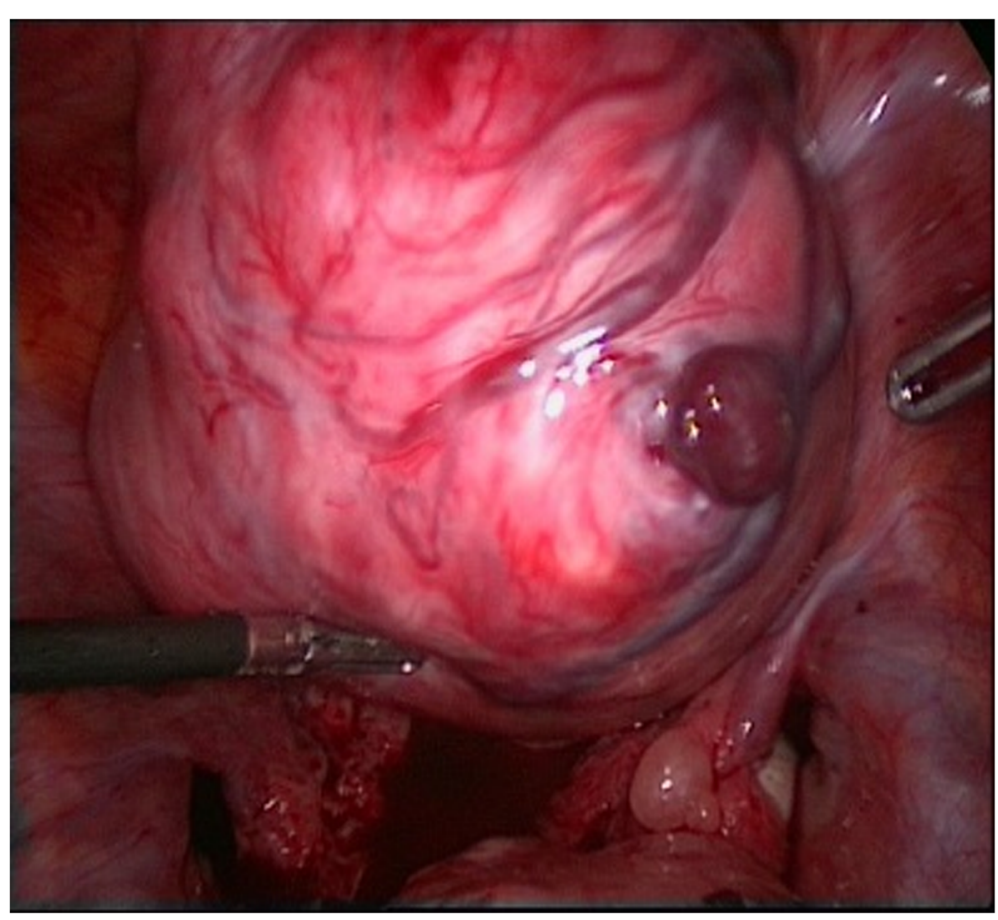

Fig. 1 Bleeding vessel on fibroma 
leiomyoma [8] rupture of a subserosal vein overlying a uterine myoma [9], bleeding from a subserosal artery [10], a lacerated leiomyoma [11], or an avulsed pedunculated leiomyoma [12]. In most cases, bleeding from a uterine leiomyoma has been associated with trauma or torsion of the tumor, but spontaneous rupture of the superficial vessels is extremely rare $[13,14]$. The source is mainly venous [8]. Increased abdominal pressure due to hard work, defecation, sports, violent coitus, pregnancy, and menstruation are predisposing factors for rupture of the superficial veins on uterine leiomyoma [9, 15]. Rupture of a blood vessel on a uterine pseudotumor leading to an isolated hemoperitoneum in the immediate postpartum period has also been reported [16, 17].

A specific preoperative diagnosis can rarely be established in these cases. In one study, the correct diagnosis was made preoperatively in a mere $7.8 \%$ of cases [18]. Computed tomography and ultrasound are able to show the hemoperitoneum but usually do not reveal the source of the bleeding [19]. The preoperative diagnosis is commonly an acute abdomen or a hemoperitoneum of unknown origin [8]. In these cases, timely diagnosis and emergent surgery, extending from ligation of the bleeding vessel to myomectomy or hysterectomy, can prevent catastrophic consequences [15]. The decision depends on the patient's age and her desire to preserve fertility [20]. Previously reported cases of hemorrhage associated with uterine leiomyoma were successfully managed with emergency laparotomy, which proved to be a lifesaving measure $[15,20]$. In our patient's case, laparoscopy was performed for the diagnosis of the source of the bleeding, the uterus was preserved during laparotomy, and the uterine leiomyoma was treated by surgical excision.

Despite its rarity, a bleeding leiomyomatous vessel should be included in the differential diagnosis of a hemoperitoneum of ambiguous origin. Rapid diagnosis and management are essential in this potentially lifethreatening condition. Surgeons should consider the possibility of this complication in women with acute abdominal pain and a history of uterine leiomyoma in order to prevent severe morbidity or even mortality. When a patient undergoes conservative management of large asymptomatic subserosal fibromas, she should be informed of this rare complication.

\section{Abbreviation}

FIGO: International Federation of Gynecology and Obstetrics

\section{Acknowledgements}

The authors are grateful to the patient for her cooperation.

\section{Authors' contributions}

SR, AMK, MK, BT, LA, and SK accrued all data, obtained the patient's informed consent, and drafted the manuscript. All authors participated in writing the manuscript. SR, LA, BT, and IA prepared the final version of the manuscript. All authors read and approved the final manuscript.
Funding

No financial support was received.

\section{Availability of data and materials}

Clinical data and complementary examinations are available from the corresponding author on reasonable request.

Ethics approval and consent to participate

For this case, no ethical approval was sought. Informed consent was obtained from the patient, and the patient's name was kept concealed.

\section{Consent for publication}

Written informed consent was obtained from the patient for publication of this case report and any accompanying images. A copy of the written consent is available for review by the Editor-in-Chief of this journal.

\section{Competing interests}

The authors have no competing interests to declare.

\section{Author details}

${ }^{1}$ Endometriosis Research Center, Iran University of Medical Science, Tehran, Iran. ${ }^{2}$ Minimally Invasive Surgery Research Center, Iran University of Medical Sciences, Tehran, Iran. ${ }^{3}$ Department of Obstetrics and Gynecology, University Hospitals Schleswig-Holstein, University Hospitals Campus Kiel, Kiel School of Gynecological Endoscopy, Arnold-Heller-Strasse 3, Haus 24, 24105 Kiel, Germany. ${ }^{4}$ Endometriosis Research Center, Rasoul Akram Hospital, Iran University of Medical Science, P.O. Box 1445613131, Tehran, Iran.

Received: 22 August 2019 Accepted: 27 March 2020

Published online: 08 May 2020

\section{References}

1. Baird DD, et al. High cumulative incidence of uterine leiomyoma in black and white women: ultrasound evidence. Am J Obstet Gynecol. 2003;188(1): 100-7.

2. Borah BJ, et al. The impact of uterine leiomyomas: a national survey of affected women. Am J Obstet Gynecol. 2013;209(4):319. e1-e20.

3. Stewart E. Uterine fibroids. N Engl J Med. 2015;372(17):1646-55.

4. Gupta S, Manyonda IT. Acute complications of fibroids. Best Pract Res Clin Obstet Gynaecol. 2009;23(5):609-17.

5. Luesley DM, Kilby MD, editors. Obstetrics \& gynaecology: an evidence-based text for the MRCOG. 3rd ed. Boca Raton: CRC Press; 2016.

6. Drutman J, Fruechte D. Hemoperitoneum due to traumatic avulsion of a pedunculated uterine leiomyoma [letter]. AJR Am J Roentgenol. 1992;158(6): 1410 .

7. Fontarensky M, et al. Acute complications of benign uterine leiomyomas: treatment of intraperitoneal haemorrhage by embolisation of the uterine arteries. Diagn Interv Imaging. 2013;94(9):885-90.

8. Sule A. Traumatic rupture of uterine fibroid: an uncommon cause of post traumatic haemoperitoneum. West Afr J Med. 2000;19(2):158-9.

9. Bou Nemer $L$, et al. Rupture of a subserosal vein overlying a leiomyoma causing hemoperitoneum. J Gynecol Surg. 2014;30(6):367-9.

10. Horowitz $\mathrm{E}$, et al. Massive hemoperitoneum due to rupture of an artery overlying a uterine leiomyoma: a case report. Acta Obstet Gynecol Scand. 2005;84(4):408-9.

11. Toquero L, Gadd R, Owers CE, Simms JM. Post-coital haemoperitoneum: a downside to intercourse. Ann R Coll Surg Engl. 2012;94(1):e26-7.

12. Estrade-Huchon $\mathrm{S}$, et al. Severe life-threatening hemoperitoneum from posttraumatic avulsion of a pedunculated uterine leiomyoma. J Minim Invasive Gynecol. 2010;17(5):651-2.

13. Dasari P, Maurya D. Hemoperitoneum associated with fibroid uterus. J Obstet Gynecol India. 2005;55(6):553-4.

14. Danikas $D$, et al. Hemoperitoneum from spontaneous bleeding of a uterine leiomyoma: a case report. Am Surg. 1999;65(12):1180-2.

15. Althobaiti FA, Alsaadi KK, Althobaiti AA. A case of hemoperitoneum due to spontaneous bleeding from a uterine leiomyoma. Am J Case Rep. 2019;20: 167-70.

16. Tan YL, Naidu A. Rare postpartum ruptured degenerated fibroid: a case report. J Obstet Gynaecol Res. 2014;40(5):1423-5. 
17. Ekane GH, Tebeu PM, Obinchemti TE, et al. Postpartum hemoperitoneum due to rupture of a blood vessel on a uterine pseudo tumor: a case report. Pan Afr Med J. 2013;16:57.

18. Deopuria R. Haemoperitoneum secondary to rupture of coronary veins on a fibroid uterus (review of world literature). J Obstet Gynecol India. 1970;20: 409-13.

19. Kamat NV, et al. Ruptured degenerated uterine fibroid diagnosed by imaging. Obstet Gynecol. 2001;98(5):961-3.

20. Jayanthi D. Hemoperitoneum due to bleeding myoma in pregnancy. Univ J Surg Surgical Spec. 2016;2(7):675-84

\section{Publisher's Note}

Springer Nature remains neutral with regard to jurisdictional claims in published maps and institutional affiliations.

Ready to submit your research? Choose BMC and benefit from:

- fast, convenient online submission

- thorough peer review by experienced researchers in your field

- rapid publication on acceptance

- support for research data, including large and complex data types

- gold Open Access which fosters wider collaboration and increased citations

- maximum visibility for your research: over $100 \mathrm{M}$ website views per year

At BMC, research is always in progress.

Learn more biomedcentral.com/submissions 